University of Nebraska - Lincoln

DigitalCommons@University of Nebraska - Lincoln

Faculty Publications, Department of Psychology

Psychology, Department of

December 2004

\title{
Understanding Perpetrators of Nonphysical Sexual Coercion: \\ Characteristics of Those Who Cross the Line
}

\author{
Sarah DeGue \\ University of Nebraska-Lincoln \\ David DiLillo \\ University of Nebraska-Lincoln, ddilillo@unl.edu
}

Follow this and additional works at: https://digitalcommons.unl.edu/psychfacpub

Part of the Psychiatry and Psychology Commons

DeGue, Sarah and DiLillo, David, "Understanding Perpetrators of Nonphysical Sexual Coercion:

Characteristics of Those Who Cross the Line" (2004). Faculty Publications, Department of Psychology. 126.

https://digitalcommons.unl.edu/psychfacpub/126

This Article is brought to you for free and open access by the Psychology, Department of at DigitalCommons@University of Nebraska - Lincoln. It has been accepted for inclusion in Faculty Publications, Department of Psychology by an authorized administrator of DigitalCommons@University of Nebraska - Lincoln. 
Published in in Violence and Victims, 19:6 (December 2004), pp. 673-688. Copyright (C 2004 Springer Publishing Company. Used by permission.

\title{
Understanding Perpetrators of Nonphysical Sexual Coercion: Characteristics of Those Who Cross the Line
}

\author{
Sarah DeGue \& David DiLillo \\ University of Nebraska-Lincoln
}

\begin{abstract}
Sexual coercion is defined here as a form of male sexual misconduct in which nonphysical tactics (e.g., verbal pressure) are utilized to gain sexual contact with an unwilling female partner. This study compares the risk characteristics of sexually coercive $(n=81)$ and nonoffending college males $(n=223)$ across several domains. Results revealed that sexual coercers differed from non offenders in that they more often subscribed to rape myths, viewed interpersonal violence as more acceptable, reported greater hostility toward females, and perceived male-female relationships as more inherently adversarial. In addition, compared to nonoffenders, sexually coercive males showed stronger indicators of promiscuity and delinquency, reported more psychopathic personality traits, had more empathic deficits, and were more likely to have experienced certain forms of childhood abuse. In most respects, coercers did not differ from those who reported engaging in more severe forms of sexual assault involving the use of physical force. These results suggest important differences between nonoffending males and those who "cross the line" by engaging in sexually coercive acts. In addition, consistent parallels can be drawn between the predictors of sexual coercion identified in this study and those documented in the sexual aggression (e.g., forcible rape) literature.
\end{abstract}

$\mathrm{S}$ exual coercion, as defined here and elsewhere (e.g., Calhoun, Bemat, Clum, \& Frame, 1997; Craig, Kalichman, \& Follingstad, 1989; DeGue \& DiLillo, in press; Koss, Leonard, Beezley, \& Gras, 1985; Lisak \& Ivan, 1995), encompasses the use of nonphysical tactics by a male to gain sexual contact (i.e., fondling, oral sex, intercourse) with a nonconsenting female partner. These tactics can include the use of lies, guilt, false promises, continual arguments, and threats to end the relationship, or ignoring verbal requests by the victims to stop (without using force). Sexual coercion may also involve the intentional use of drugs or alcohol to lower the victim's inhibitions or verbal resistance to sexual advances (i.e., getting someone "tipsy," while not rendering them physically unable to resist). Sexual aggression, by contrast, is defined here as involving the threat or use of physical force, or the use of alcohol and drugs, to impair the victim's physical ability to resist unwanted sexual contact. Although these definitions are consistent with several other researchers (e.g., see above; also Abbey, McAuslan, Zawacki, Clinton, \& Buck, 2001; Koss \& Dinero, 1988), it should be noted that these terms have sometimes been 
used interchangeably in reference to both physical and nonphysical tactics for sexual misconduct. Furthermore, other terminology has also represented each of these ideas at times (e.g., rape, sexual assault, verbal coercion, physical coercion, sexual abuse, date or acquaintance rape, sexual violence).

Although sexually coercive acts are, by definition, less severe than sexually aggressive offenses, which involve the threat or use of physical force, evidence suggests that this type of victimization is a widespread societal problem. Research on the prevalence of sexual coercion has consistently found that these behaviors occur at rates similar to or greater than those of sexual aggression, especially among college males. In an early study of sexual coercion by Koss and colleagues, $22.4 \%$ of college males reported utilizing extreme verbal pressure to obtain sexual intercourse with an unwilling female (Koss et al., 1985). Subsequent studies have found even higher rates of sexual coercion among college males. For instance, $37 \%$ (Byers \& Eno, 1991) to 69\% (Mosher \& Anderson, 1986) of college men have admitted to using verbal manipulation to engage in sex with an unwilling partner, and approximately three quarters of males reported the intentional intoxication of a female to obtain sexual intercourse (Mosher \& Anderson). Although lower rates of sexual coercion have been reported by other researchers (e.g., Abbey et al., 2001 [10\%]; Koss \& Dinero, 1988 $[7.2 \%]$ ), these rates are still similar to or greater than the rates of sexual aggression reported in comparable populations. In community samples, prevalence estimates for sexual coercion appear to be similar to or slightly lower than rates among college populations, with researchers reporting rates of male sexual coercion between 22\% (Calhoun et al., 1997) and 27\% (Senn, Desmarias, Verberg, \& Wood, 2000). Interestingly, Senn and colleagues found that $86 \%$ of the coercive males in their sample had used these tactics to obtain sexual contact on multiple occasions. It should be noted that variations in rates of self-reported sexual coercion can be influenced significantly by the methodology used. For example, many researchers (e.g., Abbey et al.; Koss \& Dinero; Koss et al., 1985) have grouped offenders by their highest level of offense (i.e., those men who report sexual coercion and aggression are categorized only as sexual aggressors), leading to lower overall rates of sexual coercion. Few researchers using this methodology have reported the number of sexual coercers within the sexually aggressive group, although this information would permit more accurate comparisons of prevalence rates across studies or populations.

In addition to evidence pointing to high rates of sexual coercion on college campuses and in the community, some preliminary research suggests that sexual coercion may be associated with negative correlates for victims. For example, Zweig, Barber, and Eccles (1997) found that college females who had experienced sexual coercion (defined as "verbal pressuring") had lower self-esteem and were more socially isolative than nonvictims. Victims of sexual coercion in this study also reported more symptoms of depression and social anxiety than either nonvictims or victims of sexual aggression. Similarly, Testa and Derman (1999) found negative associations between coercive victimization and measures of both self-esteem and assertiveness. Although it is quite possible that these characteristics predated the coercive encounters (Testa \& Derman) and therefore were not caused by coercion per se, sexual coercion may nevertheless result in short-term distress on the part of victims, such as feelings of.exploitation, vulnerability, betrayal, and shame. Of course, this form of victimization also violates an individual's right to freely determine the circumstances in which she or he engages in sexual activity.

Despite the prevalence of sexual coercion, etiological studies of sexual offending have rarely considered this form of sexual misconduct in isolation. That is, with few exceptions, most researchers have chosen to combine sexual coercion with more severe 
forms of sexual offending when exploring risk factors and characteristics associated with these behaviors (e.g., Aberle \& Littlefield, 2001; Bernat, Calhoun, \& Adams, 1999; Bernat, Calhoun, \& Stolp, 1998; Lisak, 1994; Rapaport \& Burkhart, 1984; Senn et al., 2000). This "lumping together" of offenders who use physical tactics and those who do not has made it difficult to identify any unique characteristics of sexually coercive men. For example, little is currently known about etiological factors associated specifically with the nonphysical tactics used by sexual coercers. In contrast, there is a substantial body of literature focusing on the characteristics of sexual aggressors (i.e., forcible rapists). Thus, a useful starting point for expanding current understanding of sexual coercers comes from the sexual aggression literature, which has identified various factors associated with this related form of sexual misconduct. Past research has often grouped etiological risk factors for sexual aggression into several classes of related variables. For example, Malamuth and colleagues (Malamuth, Sockloskie, Koss, \& Tanaka, 1991) used structural equation modeling to examine predictors, such as attitudes supporting aggression, delinquent and sexually promiscuous behavior, hostile masculinity personality features, and an abusive or violent home environment. Drawing on that multivariate approach, individual-level variables associated in prior literature with sexual aggression are grouped here into the following categories: (a) attitudinal or belief factors, (b) behavioral tendencies, (c) personality factors, and (d) childhood abuse experiences. What follows is a brief discussion of each of these factors and their potential relationships to sexual coercion (see DeGue \& DiLillo, in press, for a more detailed review).

\section{Attitudinal and Belief Systems}

Since the 1970s, researchers have alluded to the concept of "rape myths" as an important factor in understanding sexual offenders. It is argued that belief in these myths, based on false and stereotypical information about rape victims, rapists, and the act of rape, fosters not only a hostile and victim-blaming attitude toward rape victims, but can also encourage rape itself by providing cognitive justifications for the behavior and increasing tolerant attitudes towards offenders (Burt, 1980). Several lines of research have assessed rape-related attitudes and beliefs among sexual aggressors and, in later research, sexual coercers. In general, studies have found consistent relationships between belief in rape myths and self-reported sexual misconduct among college and community males (e.g., Byers \& Eno, 1991; Hersh \& Gray-Little, 1998; Muehlenhard \& Falcon, 1990). Other researchers have also found that angry and distrustful feelings towards women may be a factor in sexual aggression, though the results are mixed regarding sexual coercion (e.g., Abbey et al., 2001; Byers \& Eno, 1991; Calhoun et al., 1997; Malamuth, Heavey, \& Linz, 1993). In addition, studies of various negative attitudes toward women (e.g., Spence, Helrnreich, \& St.app, 1973) and cognitive distortions associated with sexual offending (e.g., Bumby, 1996) have been linked to these behaviors with some consistency. Together, these studies suggest that a wide range of attitudes and beliefs may be integral to the etiology of sexual coercion.

\section{Behavioral Tendencies}

Some evidence has amassed suggesting several behavioral variables as potential predictors of sexual aggression and coercion, including juvenile delinquency, sexual promiscuity, and generalized aggressiveness. In studying the characteristics of a large sample of college men who reported a history of sexual, nonsexual, or both types of aggression towards women, Malamuth and colleagues (1991) found that delinquency was a proximal factor in the development of both sexually and nonsexually aggressive behavior. When involvement) 
in delinquency was associated with increased promiscuity, sexually aggressive behavior was the more likely behavioral outcome. Such findings suggest that sexual and nonsexual (or generalized) aggression may be more closely related than previously thought. In fact, there is some evidence to suggest that sexually aggressive men rate higher on measures of generalized aggressiveness than do men who engage only in consensual sex (e.g., Hersh \& Gray-Little, 1998). Also, several feminist authors have argued that sexual aggression is motivated in large part by hostility or a need for power on the part of the offender, much as generalized aggression may be (e.g., Brownmiller, 1975; Groth, 1979). Finally, Malamuth (1981) introduced the concept of "rape proclivity," which refers to the likelihood that an individual "would personally rape if they could be assured of not being caught or punished" (p. 140). This study suggested that self-reported rape proclivity was related to belief in rape myths, physical arousal to rape depictions, and aggression towards females in a laboratory task. Thus, although it has received little attention, rape proclivity could prove a useful predictor of actual sexual misconduct, including coercion.

\section{Personality Factors}

Two primary personality traits - empathy and psychopathy - have emerged as important predictors of sexual aggression and, more recently, sexual coercion. Various researchers have found evidence that sexual offenders have lower overall levels of empathy than nonsexual offenders (e.g., Lindsey, Carlozzi, \& Bells, 2001; Lisak \& Ivan, 1995; Senn et al., 2000). It is possible that the presence of empathy represents an additional hurdle for potential offenders to overcome before progressing to the commission of sexually aggressive acts. For example, men with intact empathic abilities may be dissuaded from coercive acts by detecting or imagining a victim's distress or pain or by feelings of guilt or remorse afterward, whereas men with limited empathy may not. Such deficits may similarly relate to the perpetration of sexual coercion. Using various measures of psychopathy (e.g., Psychopathy Checklist, Hare, 1991; Psychopathic Personality Inventory, Lilienfeld \& Andrews, 1996), researchers have also found a positive relationship between psychopathic personality traits and sexual offending (Hare, 1998). For instance, those admitting to some form of sexual misconduct also report increased manipulativeness, sensation-seeking, and impulsivity, and lower levels of empathy in comparison to men reporting only consensual relationships (e.g., Hersh \& Gray-Little, 1998; Kosson \& Kelly, 1997; Rapaport \& Burkhart, 1984). These findings suggest that the presence of psychopathic personality traits may play an important etiological role in sexual aggression and, perhaps, in sexual coercion.

\section{Childhood Abuse Experiences}

A number of studies have examined the "cycle of abuse" theory - the notion that victims of childhood abuse may be more likely than nonvictims to perpetrate various forms of abuse as adults. Although much of this work has focused on adult perpetrators of child sexual abuse, some studies have found a relationship between child maltreatment experiences and adult rape convictions (Dhawan \& Marshall, 1996), aggression towards women (Fagan \& Wexler, 1988), and generalized aggression as adults (Widom, 1989, 2000), each suggesting that childhood maltreatment may increase an individual's risk for future sexual misconduct. Furthermore, a large-scale study by Malamuth and colleagues (1991) identified childhood maltreatment as a critical distal factor in the development of sexually violent behavior towards women. 


\section{The Present Study}

With these etiological risk factors in mind, the purpose of this paper is to shed light on several psychological and behavioral characteristics that may be specifically associated with sexual coercion. In doing so, sexually coercive college men and those reporting no such behaviors will be compared on a number of characteristics previously found to be associated with sexual aggression. Based on past sexual aggression research and the limited coercion literature, it is expected that sexually coercive men will be more likely to endorse general attitudes and beliefs encouraging interpersonal and sexual violence, to report patterns of aggressive, delinquent, and promiscuous behavior, and to have experienced various forms of childhood maltreatment. Sexual coercion is also expected to be associated with decreased empathy and concern for others.

\section{METHOD}

\section{Participants}

This study utilized a sample of 304 male college students recruited from undergraduate psychology courses at a large midwestern university. Participants ranged in age from 19 to 46 years old, with a mean age of 21.3 years $(S D=2.87)$. Most respondents reported that they had never been married (95.4\%). Although the majority of participants were White (88.2\%), other ethnicities were represented in the present sample (Asian American, 3.3\%; African American, 2.6\%; Hispanic American, 1.6\%; other, 4.2\%). Information collected from participants estimating their family's average income while growing up suggested a wide distribution of socioeconomic backgrounds, with the largest group of respondents falling in the middle to upper-middle class ranges (e.g., $\$ 41,000-\$ 60,000,26.3 \%$ ). Almost a quarter of the sample $(22.3 \%)$ reported that their parents were divorced or separated. A large majority $(85.8 \%)$ of the sample reported some religious affiliation (i.e., Protestant, 44.4\%; Catholic, 30.3\%; other, $11.2 \%$ ).

\section{Measures}

Attitudinal or Belief Systems. RAPE Scale (Bumby, 1996). The 36-item RAPE Scale was developed to assess cognitive distortions associated with sexual offending (i.e., justifications, victim blame, attitudes towards women, belief in rape myths, etc.). Designed as an updated version of the Burt (1980) scales on rape myth acceptance, this measure incorporates more current language, with many items assessing the same concepts. For example, it includes items such as "Since prostitutes sell their bodies for sexual purposes anyway, it is not as bad if someone forces them into sex," and "Women who go to bars a lot are mainly looking to have sex." Items are on a 4-point Likert-type scale, from $1=$ strongly agree to 4 = strongly disagree. Internal consistency of the RAPE scale, as reported by Bumby, was excellent, with a standardized alpha coefficient of .96. The test-retest correlation was .86 over a 2-week interval.

Adversarial Sexual Beliefs (ASB,. Burt, 1980). This nine-item measure assesses the extent to which the respondent believes that heterosexual relationships are, by nature, exploitive and manipulative (e.g., "A man's got to show the woman who's boss right from the start or he'll end up henpecked"). Items are on a 7-point Likert-type scale, from $1=$ strongly agree to $7=$ strongly disagree. Burt hypothesized that a perception of male-female relations as inherently adversarial could make an individual more susceptible to be- 
lief in rape myths (e.g., rape is on a continuum of exploitative sexual behaviors and, thus, is not unexpected).

Acceptance of Interpersonal Violence (AIV;. Burt, 1980). This six-item scale measures endorsement of the idea that violence and coercion are appropriate and legitimate methods of interpersonal interaction, particularly in sexual relationships (e.g., "Being roughed up is sexually stimulating for women"). Items are on a 7-point Likert-type scale, from $1=$ strongly agree to $7=$ strongly disagree. Burt found that AIV was the single strongest attitudinal predictor of rape myth acceptance.

Hostility Towards Women Scale (HTW; Check, 1985; Check, Malamuth, Elias, \& Barton, 1985). This 30-item scale measures angry and distrustful attitudes towards females in a true-false format (e.g., "It is safer not to trust women"). Check and colleagues reported acceptable reliability and validity for the HTW, which has been shown to correlate significantly with a history of sexual aggression.

Behavioral Tendencies. Aggression Questionnaire (AQ; Buss \& Perry, 1992). The 29item AQ was developed to assess overall aggression in males and females, as well as the individual components of aggression (e.g., "I flare up quickly, but get over it quickly"; "I sometimes feel people are laughing at me behind my back"), Factor analysis by Buss and Perry revealed four subscales of the AQ, including physical aggression, verbal aggression, anger, and hostility. Items are on a 5-point Likert-type scale, from 1 = extremely characteristic of me to $5=$ extremely uncharacteristic of me. This measure is reported to have adequate internal consistency and test-retest reliability (Buss \& Perry).

Rape Proclivity Question (Malamuth, 1981). Malamuth measured rape proclivity by asking male participants to indicate on a 5 -point scale from $1=$ not at all likely to $5=$ very likely the "likelihood that they personally would rape if they could be assured of not being caught or punished" ( $p, 140)$. Results suggested that men who indicated a greater likelihood of raping were more similar to convicted rapists in terms of their belief in rape myths and deviant sexual arousal than men who rated a lower likelihood of raping (Malamuth).

Delinquency Indicators (Malamuth et al., 1991). Two items used previously by Malamuth and colleagues to assess a history of juvenile delinquency were included in this study (i.e., "When you were growing up, did you have friends who got in trouble with the law for minor offenses [e.g., fighting or running away]?"; "When you were growing up, did you ever run away from home for more than a 24-hour period?"). Malamuth and colleagues report that these items correlate strongly with a history of delinquent behavior, including variance in the frequency and longevity of delinquency. These items were utilized in the present study, as opposed to direct questions regarding adjudicated and non-adjudicated behaviors, to limit the effects of a social desirability bias.

Promiscuity Indicators (Malamuth et al., 1991). Sexual promiscuity was assessed with two open-ended items previously utilized by Malamuth and colleagues (i.e., age of first sexual intercourse, number of sexual intercourse partners since the age of 14). Consistent with convention, current age was used as age of first intercourse for participants with no previous sexual experience in MANOVA analyses (Malamuth et al., 1991). According to Malamuth and colleagues, these variables have been used frequently to assess a history of sexual promiscuity, as well as to predict life span patterns of sexual behavior.

Personality Factors. Interpersonal Reactivity Index (IRI; Davis, 1980). The 28-item IRI consists of four subscales measuring different dimensions of empathy: perspective-taking (adopting the perspective of others), fantasy (experiencing the emotions of fictitious characters in movies, books, etc.), empathic concern (feelings of sympathy for others), and personal distress (feelings of discomfort in response to the distress of others). For exam- 
ple, items such as "When I watch a good movie, I can easily put myself in the place of a leading character" and "When I see someone who badly needs help in an emergency, I go to pieces" are representative of those that compose the fantasy and personal distress subscales, respectively. Items are on a 5-point Likert-type scale, from $1=$ strongly agree to $5=$ strongly disagree. This measure has been found to correlate positively with other measures of empathy (Davis). Davis also reported acceptable test-retest reliability coefficients (ranging from .61 to .81) and internal consistency for each subscale (ranging from .71 to .77).

Psychopathic Personality Inventory-Short Form (PPI-SF; Lilienfeld, 1990). This 56item inventory is an abbreviated version of the 187-item Psychopathic Personality Inventory (Lilienfeld), a self-report questionnaire designed to assess the presence of psychopathic personality traits on eight factor-analytically derived dimensions, referred to as Machiavellian egocentricity, social potency, coldheartedness, carefree nonplanfulness, fearlessness, blame externalization, impulsive nonconformity, and stress immunity. For example, items include "I often tell people only the part of the truth they want to hear" (Machiavellian egocentricity), "I am a good conversationalist" (social potency), "I've been the victim of a lot of bad luck in my life" (blame externalization). Lilienfeld and Andrews (1996) reported moderate to high correlations between this self-report measure of psychopathic traits and other measures of psychopathy and antisocial personality disorder, including the Psychopathy Checklist-Revised (PCL-R; Hare, 1991). Items are on a 4-point Likert-type scale, from $1=$ false to $4=$ true. The short form of the PPI was developed by including the seven items from each subscale that loaded most highly on each of the eight dimensions (Lilienfeld). The PPI-SF has been found to correlate $(r=.90)$ with the PPI full form, with an internal consistency of .85 overall and a range of .64 to .85 for the subscales. Only the PPI total scale score is utilized in the present study to assess levels of psychopathic personality traits.

Childhood Abuse Experiences. Computer Administered Maltreatment Inventory (CAMI; Nash, DiLillo, Messman-Moore, \& Rinkol, 2002). The CAMI provides a comprehensive assessment of multiple forms of child maltreatment experiences (i.e., sexual abuse, physical abuse, neglect, psychological abuse, and witnessing parental violence), while allowing for a simplified method of collecting detailed information about co-occurring abuse types. Using a screening page and extensive follow-up questions, the presence of each type of child maltreatment was assessed for the purposes of this study. The CAMI utilizes researcher-defined question formats to avoid the methodological difficulties of relying on personal definitions of abuse (e.g., Were you ever sexually abused?). In addition, the computer-administration may provide participants with an increased perception of confidentiality, leading to full-disclosure of sensitive experiences. Preliminary evjdence of criterion related validity and acceptable 2-week test-retest reliability has been reported (Nash et al., 2002).

Assessment of Sexual Misconduct. Sexual Experiences Questionnaire (SEQ; Lisak \& Roth, 1988). A history of sexually coercive and aggressive behavior was assessed using an 11-item version of the SEQ. The SEQ is a modified version of the Sexual Experiences Survey (SES; Koss \& Oros, 1982), a measure of sexual behavior utilized extensively in past research on sexual misconduct. Both measures include items assessing the use of lies, false promises, continual arguments, threats to end the relationship, drug or alcohol impairment, and threats or use of physical force to obtain sexual contact. The SEQ includes an additional item assessing whether the respondent had persisted in having sexual intercourse with a woman, without using physical force, despite her verbal attempts to stop him. Items are on a 5-point Likert-type scale, from $1=n e v e r$ to $5=$ often. An internal consistency reliability coefficient of .89 for college men and a 1-week test-retest reliability with a mean item agreement of $93 \%$ was reported by Koss and Gidycz (1985) for the SES. In development 
of the SEQ, Koss and Oros 's SES items were modified slightly to improve clarity, though their original meaning was maintained. The 29-item SEQ includes additional questions regarding various motivations for sexual misconduct that were not included in this study. The abbreviated version of the SEQ utilized here included items 1 and 20 to 29 from the original questionnaire designed by Lisak and Roth. For the purposes of this article, sexual coercion was defined as including SEQ items 20 to 22, and 24, whereas sexual aggression was defined as including items 23 and 25 to 28 . Lisak and Roth conducted a small-scale assessment of validity for the SEQ using post test interviews and reported "a greater degree of validity . . . than was earlier reported" for the SES, which may be attributable to the rewording of items in the SEQ.

Procedure. Participants were recruited from psychology courses and offered extra course credit for participation in accordance with their class policies. Because the present study is Internet-based, students were provided with the URL for the study, as well as a unique login code to allow them access to the website. Before entering the study, all participants were presented with a consent form that explained that the current study was designed to "investigate the relationship of a wide variety of personality characteristics and behaviors." Participants were told that they would be asked to provide information about "many of your attitudes, beliefs, and behaviors, including certain sexual experiences you mayor may not have had." In addition, they were informed that their responses would be entirely confidential, would not be identified by their name, and that the data would be stored on a password-protected computer in the psychology department. All participants completed the demographic questionnaire, SEQ, and CAMI, in that order. The remaining questionnaires were presented in a randomized sequence to avoid order effects.

\section{RESULTS}

\section{Prevalence of Sexual Coercion and Aggression}

Of the full sample, $31.9 \%(n=97)$ reported engaging in sexual coercion, defined as inappropriate male sexual behavior in which nonphysical tactics (e.g., deceit, threats to end the relationship, continual arguments, or ignoring verbal requests to stop) are utilized to obtain sexual intercourse with an unwilling partner. Sixteen coercive individuals who also reported higher levels of sexual misconduct were classified as sexual aggressors for the purposes of these analyses. Therefore, the sample of sexual coercers utilized comprised $26.6 \%(n$ $=81$ ) of the full sample of college males. Figure 1 shows a breakdown of the types of coercion endorsed by these participants. Nearly a third of the coercive sample $(29.6 \%)$ endorsed the use of more than one sexually coercive tactic. Thus, the categories shown in Figure 1 are not mutually exclusive. The most common form of sexual coercion, utilized by $86.4 \%$ $(n=70)$ of the coercive group at least once, involved obtaining sexual intercourse with an unwilling female by "making her think that I cared for her more than I really did." In addition to this common form of sexual coercion, $24.7 \%(n=20)$ of coercive respondents reported that they had persisted in having sexual intercourse with a woman, without the use of physical force, despite verbal attempts by the victim to stop them. Further, the use of continual arguments $(18.5 \% ; n=15)$ and threats to end the relationship $(2.5 \% ; n=2)$ were also reported by the sexually coercive men. Our definition of coercion also includes the intentional use of drugs or alcohol to reduce the victim's inhibitions (while not rendering her unable to physically resist). However, due to ambiguities regarding the level of victim impairment in the wording of the related SEQ item (i.e., "getting her too drunk to resist"), this 


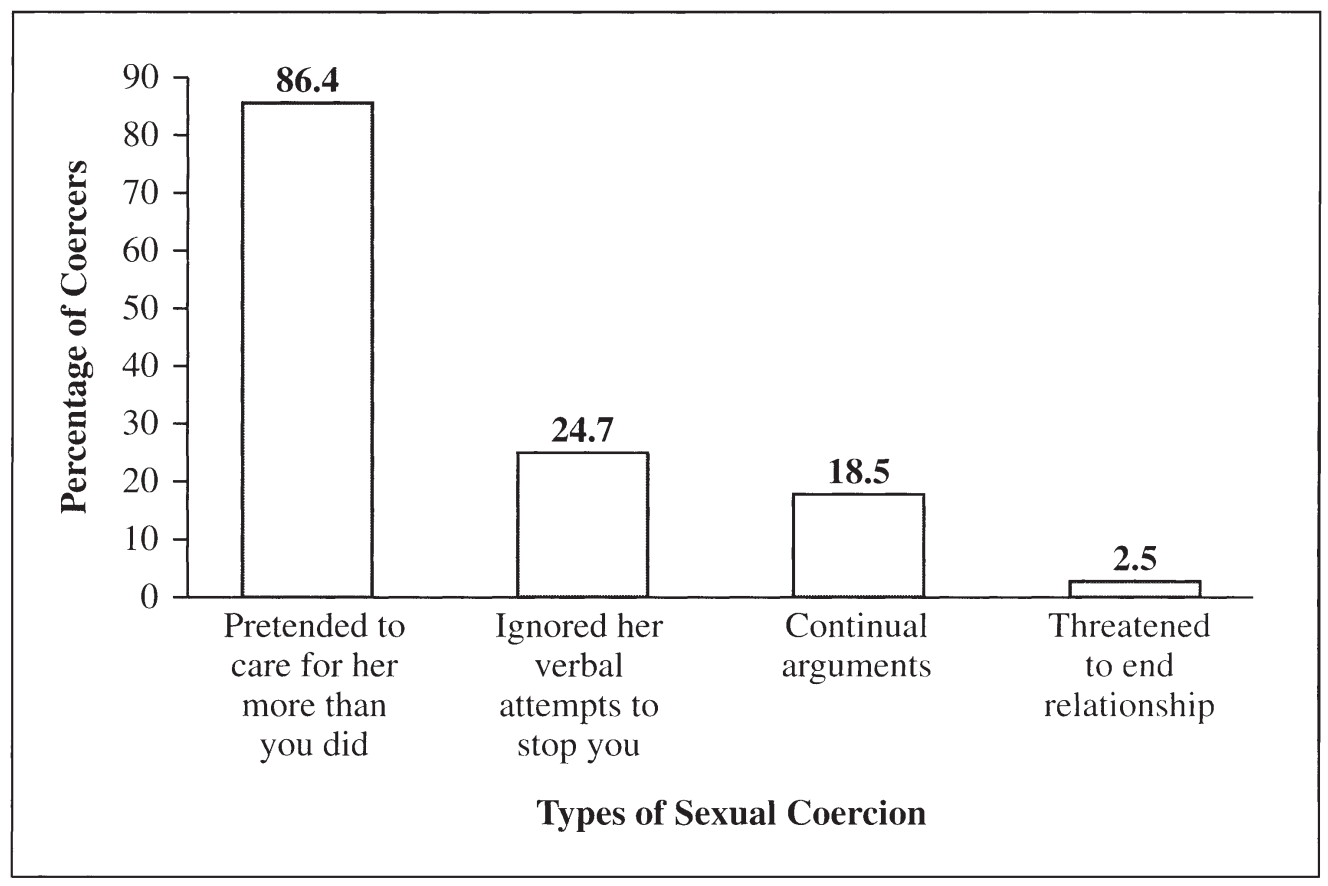

Figure 1. Types of sexual coercion endorsed.

item was ultimately determined to better reflect the use of a sexually aggressive tactic in which the victim is physically unable to resist the perpetrator's advances. This is also consistent with past researchers who have noted that legal definitions of rape often include the use of alcohol or drugs to substantially impair the victim's judgment or control and prevent resistance (e.g., Koss, Gidycz, \& Wisniewski, 1987).

In contrast, a smaller proportion of respondents $(5.9 \% ; n=18)$ reported engaging in sexually aggressive behavior. The most common form of sexual aggression, endorsed by $77.8 \%$ ( $n=14)$ of this subsample, involved deliberately getting a woman "too drunk to resist." The next most common tactics reported by sexual aggressors included the use or threat of physical force to obtain oral sex $(16.6 \% ; n=3)$ or kissing or fondling $(11.1 \% ; n=2)$. Attempted rape ("tried but did not succeed in using physical force to obtain sex") was also reported by $11.1 \%(n=2)$, while no participants reported having successfully obtained sexual intercourse through the use of physical force. The vast majority of sexual aggressors also endorsed the use of coercive tactics $(88.9 \% ; n=16)$. As noted above, these respondents were classified as sexual aggressors based on their most serious offense and were not included in the coercive sample. The most common forms of coercion used by sexual aggressors corresponded to the most common forms among those who used only coercive tactics (deception regarding his feelings for her, 83.3\%; ignoring verbal attempts to stop him, 33.3\%).

\section{Comparisons of Coercive and Non-Offending Participants}

Because of the relatively large number of comparisons to be made between sexual coercers and nonoffenders, overall MANOVA analyses were conducted to control inflation of alpha levels. Sexual coercion perpetration status (none vs. any) was entered in MANOVA analyses as the independent variable, and each of the continuous variables in Table 1 were 
included as dependent variables. These analyses did not include categorical delinquency indicators or childhood maltreatment variables. MANOVA analyses were conducted for three variable sets, as listed in Table 1. Each of the three MANOVAs performed was significant: attitudinal/belief, $F(4,281)=7.52, p<.001$; behavioral, $F(3,282)=16.86, p<.001$; and personality, $F(2,283)=11.86, p<.001$; therefore, follow-up ANOVA analyses were conducted. Chi-square analyses were used for the categorical variables of delinquency and childhood maltreatment. These results are presented in Table 1 and discussed in detail in the following sections.

Attitudinal or Belief Systems. Participants reporting sexually coercive behavior differed significantly from nonoffenders on each of the attitudinal/belief measures utilized in this study. Specifically, coercers reported a stronger belief in rape myths than did nonoffenders, as indicated by their responses on the Rape Scale (Bumby, 1996). In addition, coercive and nonoffending men differed significantly on two of the Burt (1980) scales, Acceptance of Interpersonal Violence and Adversarial Sexual Beliefs. By reporting significantly higher scores on these scales, coercive men indicated an increased belief that sexual relationships are inherently exploitive and that violent behavior is an appropriate element of interpersonal relationships. Finally, coercive males endorsed more anger and distrust of females than did nonoffenders, as evidenced by their significantly higher mean on the Hostility Towards Women scale (Check et al., 1985).

Behavioral Tendencies. As hypothesized, sexually coercive males displayed greater overall levels of generalized aggression on the Aggression Questionnaire (Buss \& Perry, 1992) than did nonoffending participants. Furthermore, coercers reported greater levels of promiscuity as indicated by having more sexual partners and an earlier age of first intercourse than nonoffenders. Regarding the delinquency indicators, coercive men were more likely than nonoffending men to have delinquent peers as children or adolescents, but were not statistically more likely to indicate a history of running away as youths. However, the pattern of frequencies for runaway history $(3.4 \%$ vs. $7.2 \%)$ was in the hypothesized direction, suggesting that a larger sample size may have resulted in a statistically significant difference. Finally, although mean scores on the rape proclivity item (Malamuth, 1981) were low for both groups, sexually coercive men reported a significantly greater likelihood that they would rape if assured they would not be caught.

Personality Factors. Consistent with hypotheses, coercive men endorsed higher levels of psychopathic personality traits than did nonoffending men, as measured by the Psychopathic Personality Inventory (Lilienfeld, 1990; see Table 1). In addition, results indicated that sexually coercive men scored higher than nonoffending men on the Interpersonal Reactivity Index (Davis, 1996), a measure of empathic deficits, suggesting that coercers may have a lower overall capacity for empathy.

Childhood Abuse Experiences. As hypothesized, sexually coercive men were more likely than nonoffenders to have experienced certain forms of child maltreatment. Specifically, coercers more often endorsed childhood histories of physical and psychological abuse, as assessed by the CAMI (Nash et al., 2002). However, findings showed that the two groups did not differ in regards to their sexual abuse, witnessing of parental violence, or neglect experiences.

\section{Supplemental Analyses}

Comparisons of Sexually Coercive and Aggressive Participants. Although the primary goal of this study was to examine unique characteristics of sexually coercive versus non- 
TABLE 1. Mean Scores and Frequencies for Nonoffenders and Coercers

\begin{tabular}{|c|c|c|c|}
\hline Characteristics & $\begin{array}{l}\text { Nonoffenders } \\
(n=205) \\
(S D) / \%\end{array}$ & $\begin{array}{l}\begin{array}{c}\text { Coercers } \\
(n=81)\end{array} \\
M(S D) / \%\end{array}$ & $F(1,195) / \chi^{2}$ \\
\hline \\
\hline $\begin{array}{l}\text { Attitudinal/Belief Systems } \\
\text { Belief in Rape Myths (RS) }\end{array}$ & $123.7(14.6)$ & $117.0(12.7)$ & $13.0^{* *}$ \\
\hline \multicolumn{3}{|l|}{ Acceptance of Interpersonal } & $23.4 * *$ \\
\hline \multicolumn{3}{|l|}{ Adversarial Sexual Beliefs } & $16.1 * *$ \\
\hline $\begin{array}{l}\text { Hostility Toward Women } \\
\text { (HTW) }\end{array}$ & $8.0(4.6)$ & $9.9(5.4)$ & $9.5^{* *}$ \\
\hline \multicolumn{4}{|l|}{ Behavioral Tendencies } \\
\hline $\begin{array}{l}\text { Promiscuity indicators } \\
\text { Age of first intercourse } \\
\text { Number of sex partners }\end{array}$ & $\begin{array}{r}17.4(1.8) \\
2.1(5.9)\end{array}$ & $\begin{array}{r}16.6(1.5) \\
6.6(8.1)\end{array}$ & $\begin{array}{r}8.9 * * \\
26.9 * *\end{array}$ \\
\hline \multicolumn{4}{|l|}{ Delinquency indicators } \\
\hline $\begin{array}{l}\text { Delinquent peers } \\
\text { Runaway history }\end{array}$ & $\begin{array}{l}61.4 \% \\
3.4 \%\end{array}$ & $\begin{array}{r}76.5 \% \\
6.2 \%\end{array}$ & $\begin{array}{l}5.9 * \\
1.1\end{array}$ \\
\hline Rape proclivity (LTR) & $1.2(0.7)$ & $1.5(1.0)$ & $7.7 * *$ \\
\hline \multicolumn{4}{|l|}{ Psychopathic personality } \\
\hline $\begin{array}{l}\text { traits (PPI) } \\
\text { Empathic deficits (IRI) }\end{array}$ & $\begin{array}{r}126.4(12.0) \\
76.0(10.9)\end{array}$ & $\begin{array}{r}133.6(11.2) \\
79.4(10.7)\end{array}$ & $\begin{array}{l}13.0^{* *} \\
5.7^{*}\end{array}$ \\
\hline \multicolumn{4}{|l|}{$\begin{array}{l}\text { History of Childhood } \\
\text { Maltreatment }\end{array}$} \\
\hline Sexual abuse & $6.8 \%$ & $7.4 \%$ & 0.03 \\
\hline Physical abuse & $57.1 \%$ & $74.1 \%$ & $7.1 * *$ \\
\hline Psychological abuse ${ }^{c}$ & $34.1 \%$ & $51.9 \%$ & $7.6^{* *}$ \\
\hline Witnessing parental violence & $13.7 \%$ & $22.2 \%$ & 3.2 \\
\hline Neglect $^{\mathrm{c}}$ & $37.6 \%$ & $45.7 \%$ & 1.6 \\
\hline
\end{tabular}

${ }^{\mathrm{a}}$ Lower scores indicate more endorsement of the attribute assessed. ${ }^{\mathrm{b}}$ Age of first intercourse analyses were based on a sample of 191 participants with previous sexual

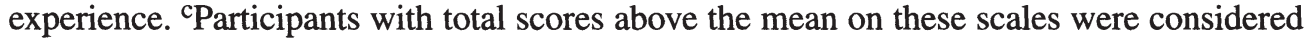
to have experienced these abuse types for the purposes of this study.

${ }^{*} p<.05 .{ }^{*} p<.01$.

offending males, a small number of participants did report sexually aggressive behaviors $(5.9 \% ; n=18)$. In order to provide an initial look at possible similarities or differences between these individuals and sexual coercers, supplemental ANOVA and chi-square analyses were conducted to compare these groups on each of the variables assessed. Results indicated that sexually aggressive men did not differ from sexually coercive men on any of these variables, with the exception of belief in rape myths, which was significantly stronger for sexual aggressors than coercers, $F(1,97)=11.17, p<.01$. These results must be considered preliminary due to the small sample of aggressors.

Assessing Potential Effects of Sexual Experience. Interestingly, almost a third of the full sample of college males $(31.9 \%, n=97)$ reported that they had never engaged in sexual intercourse. Because these sexually inexperienced men (i.e., "virgins") comprised $46.3 \%$ 
$(n=95)$ of the nonoffender group and only $1 \%(n=1)$ of the coercer group, further analyses were conducted to assess the potential effects of the disproportionate distribution of these participants on the group means. Specifically, the nonoffending sample was split into sexually experienced non offenders and sexually inexperienced nonoffenders. ANOVA and chisquare analyses were again conducted to compare these two groups on each of the variables assessed (except promiscuity indicators). Results indicated that sexually experienced and inexperienced nonoffending men did not differ significantly on any of the variables assessed. Thus, the greater presence of sexually inexperienced men in the nonoffending group did not appear to account for the differences found between the two primary groups of interest (i.e., coercers and nonoffenders).

\section{DISCUSSION}

The present results are consistent with past research suggesting that sexual coercion is a widespread problem on college campuses. In fact, our findings that nearly one out of three males reported engaging in sexually coercive behavior are somewhat greater than the rates reported in some other studies of college males (e.g., Koss et al., 1985). Greater disclosure rates may, in part, be attributable to an increased sense of privacy and anonymity associated with the Web-based design of this study, which permitted participants to complete measures in a location of their choosing without face-to-face contact with the researchers. This possibility is consistent with other findings of increased reporting of sexual behavior among adolescents using computer-based assessments (Turner, Ku, Rogers, Lindberg, Pleck, \& Sonenstein, 1998). Notably, the rate of sexually coercive behavior was even greater when examining only those participants who had previously engaged in sexual intercourse $(31.9 \%$ of the full sample vs. $46.4 \%$ of the sexually experienced subsample). Although few past researchers have reported rates of sexual coercion among sexually experienced males specifically, these results suggest that this distinction may be important to make in future research.

The current data supported hypotheses regarding possible etiological factors associated with sexual coercion in each of the four dimensions assessed. Results revealed that sexually coercive males differed from nonoffending men in that they more often subscribed to rape myths, were more likely to view interpersonal violence as acceptable, had increased feelings of anger and distrust toward females, and perceived male-female relationships as more inherently adversarial. In addition, compared to nonoffenders, coercive males showed stronger indicators of promiscuity and juvenile delinquency, possessed more psychopathic personality traits and less empathy, and indicated a greater likelihood that they would rape if assured of not being caught. Finally, the sexually coercive men were more likely to have a history of child physical and psychological abuse than nonoffenders. Together, these findings complement and extend the broader sexual misconduct literature by identifying risk characteristics specific to sexually coercive men. These findings-that coercive and nonoffending men can be differentiated on the basis of a variety of cognitive, personality, behavioral, and experiential factors-mirror past research (e.g., Malamuth et al., 1991) that has identified similar variables as important risk factors for sexual aggression.

Consistent parallels between the characteristics of sexual coercers and those established in the sexual aggression literature suggest that these forms of sexual behavior may share a common etiology or set of risk factors. Further support for this idea was provided by supplemental analyses directly comparing sexually coercive and aggressive men in the current study, with results suggesting that these groups did not differ on any of the factors assessed except belief in rape myths. As noted, however, the low rates of sexual aggression reported 
by this sample $(5.9 \% ; n=18)$ make these findings preliminary. Future research should explore whether group differences emerge within a larger sample of sexual aggressors. In addition, although the present study focused on a range of individual-level characteristics associated with coercive offending, other work examining peer support for sexual violence (DeKeseredy \& Schwartz, 2000; DeKeseredy \& Kelly, 1995) and victim alcohol use (e.g., Abbey, Clinton-Sherrod, McAuslan, Zawacki, \& Buck, 2003; Ullman, Karabatsos, \& Koss, 1999) suggests the need to include these factors in future studies of coercion.

The results reported here for sexual coercers raise the possibility-also suggested by Testa and Derman (1999) - that sexual coercion may serve as an important precursor to more severe forms of sexual misconduct. That is, males who engage in sexual coercion may eventually progress to more serious sexually assaultive behaviors. (As noted, 16 of the 18 participants who admitted to sexually aggressive behaviors also reported engaging in sexually coercive behavior.) Currently, however, the exact relationship between sexual coercion and more severe sexual offending is not well understood. One possibility is that sexual coercion serves as a "gateway" to more serious sexual aggression. Perhaps "successfully" engaging in sexual coercion (i.e., reaping sexual benefits without experiencing negative consequences) fosters a favorable perception of sexually inappropriate behavior generally, thereby increasing the likelihood that an individual will engage in more aggressive forms of sexual offending in the future. Another possibility, suggested by the present results, is that the presence of certain risk factors (e.g., belief in rape myths, nonsexual aggression, promiscuity, psychopathic traits, child maltreatment) may increase the probability that an individual will perpetrate some type of sexual misconduct. The combined intensity of these risk factors may impact whether an individual engages only in lower-level coercive acts or eventually progresses to more severe sexual offending. Unfortunately, no large-scale studies to date have directly compared sexually coercive and aggressive men on a comprehensive set of risk factors to illuminate characteristics that might link or differentiate these forms of sexual misconduct. Thus, further research, particularly a longitudinal investigation that starts with coercion-only offenders, will be needed to better understand the relationship between sexual coercion and aggression.

This study did not find differences between coercive and nonoffending men in regard to runaway experiences, sexual abuse history, exposure to parental violence, or childhood neglect. Most notable among these findings may be the lack of association between sexual coercion and child sexual abuse, a factor that has been studied extensively in relation to sexual aggression (e.g., Dhawan \& Marshall, 1996; Simons, Wurtele, \& Heil, 2002). Although the experience of child sexual abuse has been cited as an important predictor of adult sexual offending, there is some evidence suggesting that this link may be most apparent for those who perpetrate sexual crimes against children (Simons et al., 2002). These authors also suggested a unique association between a history of physical abuse (rather than sexual abuse) and the sexual victimization of adult women (e.g., rape). Consistent with this literature, the present study found that sexual coercion of adult women was not related to a history of child sexual abuse but was strongly associated with childhood physical abuse.

Limitations of the present study should be noted. First, it is possible that some sexual coercers in this sample also engaged in sexually aggressive behaviors that they simply did not disclose. The presence of sexual aggressors in the coercive sample could, in part, account for the similarities observed between these types of offenders. However, as noted, the rates of sexual coercion and aggression found here are comparable to those in past research with the SES (e.g., Byers \& Eno, 1991; Lisak \& Roth, 1988; Mosher \& Anderson, 1986). A related issue involves the use of retrospective, self-report measures to assess sensitive infor- 
mation about participants' sexual behavior, as this methodology may be susceptible to intentional (e.g., purposeful underreporting) and unintentional (e.g., memory error) inaccuracies. Finally, this study examined coercive behavior among primarily White, college males. Although this is an important area of focus given the high rates of offending on college campuses, these results should not be generalized to the larger population of coercers.

The results of the present study have implications for sexual misconduct prevention efforts, especially on college campuses. First, increased knowledge about the characteristics associated specifically with sexual coercion can help identify, for prevention efforts, individuals at risk of engaging in these behaviors. Involving these at-risk males in prevention programming prior to their first sexual experience may prove especially effective at reducing the likelihood that they will subsequently engage in sexual coercion. Second, if future research provides evidence that sexual coercion is indeed a precursor to more serious sexually aggressive acts, it may be possible to prevent escalation to higher levels of offending by .targeting those men who are at risk for or who have already engaged in sexually coercive behaviors. Finally, prevention efforts that specifically address the full range of sexually inappropriate behaviors, from sexual coercion to forcible rape, and that highlight even "low level" sexually coercive tactics as problematic and inappropriate, may be critical to increasing awareness of this form of sexual misconduct and promoting responsible male sexual behavior.

\section{REFERENCES}

Abbey, A., Clinton-Sherrod, A. M., McAuslan, P., Zawacki, T., \& Buck, P. (2003). The relationship between the quantity of alcohol consumed and the severity of sexual assaults by college men. Journal of Interpersonal Violence, 18(7),813-833.

Abbey, A., McAuslan, P., Zawacki, T., Clinton, A. M., \& Buck, P. (2001). Attitudinal, experiential, and situational predictors of sexual assault perpetration. Journal of Interpersonal Violence, 16(8), 784-807.

Aberle, C., \& Littlefield, R. (2001). Family functioning and sexual aggression in a sample of college men. Journal of Interpersonal Violence, 16(6), 565-579.

Bernat, J., Calhoun, K., \& Adams, H. (1999). Sexually aggressive and nonaggressive men: Sexual arousal and judgments in response to acquaintance rape and consensual analogues. Journal of Abnormal Psychology, 108(4), 662-673.

Bernat, J., Calhoun, K., \& Stolp, S. (1998). Sexually aggressive men's response to a date rape analogue: Alcohol as a disinhibiting cue. Journal of Sex Research, 35(4), 341-348.

Brownmiller, S. (1975). Against our will: Men, women, and rape. New York: Simon and Schuster.

Bumby, K. M. (1996). Assessing the cognitive distortions of child molesters and rapists: Development and validation of the MOLEST and RAPE scales. Sexual Abuse: A Journal of Research and Treatment, 8(1), 37-54.

Burt, M. (1980). Cultural myths and supports for rape. Journal of Personality and Social Psychology, 38, 217-230.

Buss, A. H., \& Perry, M. (1992). The Aggression Questionnaire. Journal of Personality and Social Psychology, 63, 452-459.

Byers, E., \& Eno, R. (1991). Predicting men's sexual coercion and aggression from attitudes, dating history, and sexual response. Journal of Psychology and Human Sexuality, 4(3), 55-69.

Calhoun, K. S., Bernat, J. A., Clum, G. A., \& Frame, C. L. (1997). Sexual coercion and attraction to sexual aggression in a community sample of young men. Journal of Interpersonal Violence, 12(3), 392-406. 
Check, J. V. P. (1985). The Hostility Toward Women Scale (Doctoral Dissertation, University of Manitoba, 1985). Dissertation Abstracts International, 45, 3993.

Check, J. V. P., Malamuth, N. M., Elias, B., \& Barton, S. (1985, April). On hostile ground. Psychology Today, pp. 56-61.

Craig, M. E., Kalichman, S., \& Follingstad, D. (1989). Verbal coercive sexual behavior among college students. Archives of Sexual Behavior; 18(5), 421-434.

Davis, M. H. (1980). A multidimensional approach to individual differences in empathy. JSAS Catalog of Selected Documents in Psychology, 10, 85.

Davis, M. H. (1996). Empathy: A social psychological approach. Boulder, CO: Westview.

DeGue, S., \& DiLillo, D. (in press). "You would if you loved me": Toward an improved conceptual and etiological understanding of male sexual coercion. Aggression and Violent Behavior.

DeKeseredy, W., \& Kelly, K. (1995). Sexual abuse in Canadian university and college dating relationships: The contribution of male peer support. Journal of Family Violence, 10(1), 41-53.

Dhawan, S., \& Marshall, W. L. (1996). Sexual abuse histories of offenders. Sexual Abuse: A Journal of Research and Treatment, 8(1), 7-15.

Fagan, J., \& Wexler, S. (1988). Explanations of sexual assault among violent delinquents. Journal of Adolescent Research, 3, 363-385.

Groth, A. N. (1979). Men who rape: The psychology of the offender. New York: Plenum.

Hare, R. (1991). The Hare Psychopathy Checklist-Revised. Toronto, Canada: Multi-Health Systems.

Hare, R. (1998). Psychopaths and their nature: Implications for the mental health and criminal justice systems. In T. Millon, E. Simonsen, M. Birket-Smith, \& R. D. Davis (Eds.), Psychopathy: Antisocial. criminal and violent behavior. New York: Guilford Press.

Hersh, K., \& Gray-Little, B. (1998). Psychopathic traits and attitudes associated with self-reported sexual aggression in college men. Journal of Interpersonal Violence, 13, 456-471.

Koss, M. P., \& Dinero, T. E. (1988). Predictors of sexual aggression among a national sample of male college students. In R. A. Prentky \& V. L. Quinsey (Eds.), Human sexual aggression: Current perspectives (pp. 133-147). New York: Annals of the New York Academy of Sciences.

Koss, M. P., \& Gidycz, C. A. (1985). Sexual experiences survey: Reliability and validity. Journal of Consulting and Clinical Psychology, 53, 422-423.

Koss, M. P., Gidycz, A., \& Wisniewski, N. (1987). The scope of rape: Incidence and prevalence of sexual aggression and victimization in a national sample of higher education students. Journal of Consulting and Clinical Psychology, 55(2), 162-170.

Koss, M. P., Leonard, K. E., Beezley, D. A., \& Oros, C. J. (1985). Nonstranger sexual aggression: A discriminant analysis of the psychological characteristics of undetected offenders. Sex Roles, 12, 981-992.

Koss, M., \& Oros, C. J. (1982). Sexual Experiences Survey: A research instrument investigating sexual aggression and victimization. Journal of Consulting and Clinical Psychology, 50, 455-457.

Kosson, D. S., \& Kelly, J. C. (1997). Psychopathy-related traits predict self-reported sexual aggression among college men. Journal of Interpersonal Violence, 12, 241-258.

Lilienfeld, S. O. (1990). Development and preliminary validation of a self-report measure of psychopathic personality. Unpublished doctoral dissertation, University of Minnesota, Minneapolis, $\mathrm{MN}$.

Lilienfeld, S. O., \& Andrews, B. P. (1996). Development and preliminary validation of a self-report measure of psychopathic personality traits in noncriminal populations. Journal of Personality Assessment, 66, 488-524.

Lindsey, R. E., Carlozzi, A. F., \& Eells, a. T. (2001). Differences in the dispositional empathy of juvenile sex offenders, non-sex-offending delinquent juveniles, and nondelinquent juveniles. Journal of Interpersonal Violence, 16, 510-522. 
Lisak, D. (1994). Subjective assessment of relationships with parents by sexually aggressive and nonaggressive men. Journal of Interpersonal Violence, 9(3), 399-411.

Lisak, D., \& Ivan, C. (1995). Deficits in intimacy and empathy in sexually aggressive men. Journal of Interpersonal Violence, 10, 296-308.

Lisak, D., \& Roth, S. (1988). Motivational factors in nonincarcerated sexually aggressive men. Journal of Personality and Social Psychology, 55, 795-802.

Malamuth, N. M. (1981). Rape proclivity among males. Journal of Social Issues, 37, 138-157.

Malamuth, N. M., Heavey, C. L., \& Linz, D. (1993). Predicting men's antisocial behavior against women: The interaction model of sexual aggression. In G. N. Hall, J. Hirschman, J. Graham, \& M. Zaragoza (Eds.), Sexual aggression: Issues in etiology, assessment and treatment (pp. 63-97). Washington, DC: Hemisphere.

Malamuth, N. M., Sockloskie, R. J., Koss, M. P., \& Tanaka, J. S. (1991). Characteristics of aggressors against women: Testing a model using a national sample of college students. Journal of Consulting and Clinical Psychology, 59, 670-681.

Mosher, D. L., \& Anderson, R. D. (1986). Macho personality, sexual aggression, and reactions to guided imagery of realistic rape. Journal of Research in Personality, 20, 77-94.

Muehlenhard, C., \& Falcon, P. (1990). Men's heterosocial skill and attitudes toward women as predictors of verbal sexual coercion and forceful rape. Sex Roles, 23, 241-259.

Nash, C. L., DiLillo, D., Messman-Moore, T. L., \& Rinkol, S. (2002, November). The Computer Assisted Maltreatment Inventory (CAMI): An investigation of test-retest reliability and criterion validity. Poster presented at the meeting of the Association for the Advancement of Behavior Therapy, Reno, NV.

Rapaport, K., \& Burkhart, B. R. (1984). Personality and attitudinal characteristics of sexually coercive college males. Journal of Abnormal Psychology, 93, 216-221.

Scwartz, M., \& DeKeserdey, W. (2000). Aggregation bias and woman abuse: Variations by male peer support, region, language, and school type. Journal of Interpersonal Violence, 15(6), 555-565.

Senn, C., Desmarias, S., Verberg, N., \& Wood, E. (2000). Predicting coercive sexual behavior across the lifespan in a random sample of Canadian men. Journal of Social and Personal Relationships, 17(1), 95-113.

Simons, D., Wurtele, S. K., \& Heil, P. (2002). Childhood victimization and lack of empathy as predictors of sexual offending against women and children. Journal of Interpersonal Violence, 17(12), 1291-1307.

Spence, J. T., Helmreich, R., \& Stapp, J. A. (1973). A short version of the Attitudes Towards Women Scale. Bulletin of the Psychonomic Society, 2, 219-220.

Testa, M., \& Derman, K. H. (1999). The differential correlates of sexual coercion and rape. Journal of Interpersonal Violence, 14, 548-561.

Turner, C. F., Ku, L., Rogers, S. M., Lindberg, L. D., Pleck, J. H., \& Sonenstein, F. L. (1998). Adolescent sexual behavior, drug use, and violence: Increased reporting with computer survey technology. Science, 280, 867-873.

Ullman, S., Karabatsos, G., \& Koss, M. (1999). Alcohol and sexual assault in a national sample of college women. Journal of Interpersonal Violence, 14(6), 603-625.

Widom, C. S. (1989). Child abuse, neglect and adult behavior: Research design and findings on criminality, violence, and child abuse. American Journal of Orthopsychiatry, 58, 260-270.

Widom, C. S. (2000). Motivation and mechanisms in the cycle of violence. In D. J. Hansen (Ed.), Motivation and child maltreatment (vol. 46). Lincoln: University of Nebraska Press.

Zweig, J. M., Barber, B., \& Eccles, J. (1997). Sexual coercion and well-being in adulthood: Comparisons by gender and college status. Journal of Interpersonal Violence, 12, 291-308. 